\title{
TI.52.2
}

\section{Local Domain Person Object Class Study}

- HTML: internet2-mace-dir-localdomainperson-200505.html

\section{More Information}

\begin{tabular}{|l|l|}
\hline Repository ID & TI.52.2 \\
\hline Persistent URL & http://doi.org/10.26869/TI.52.2 \\
\hline Title & Local Domain Person Object Class Study \\
\hline Authors & Brendan Bellina \\
\hline Sponsor & NMI-Edit \\
\hline Review & \\
\hline Status & Legacy \\
\hline Publish Date & May, 2005 \\
\hline DOI & $10.26869 / T I .52 .2$ \\
\hline Signature & \\
\hline Deprecated & No \\
\hline Future Review & \\
\hline Supersedes & TI.52.1 \\
\hline Format & HTML \\
\hline Related Docs & \\
\hline Development Location & \\
\hline IP Framework & middlewarerescue \\
\hline Subject Tags & \\
\hline Notes & \\
\hline
\end{tabular}

